\title{
Teaching Trump: Why Comparative Politics Makes Students More Optimistic about US Democracy
}

Hannah Baron, Brown University

Robert A. Blair, Brown University

Shelby Grossman, University of Memphis

ABSTRACT How does learning about democratic erosion in other countries shape opinions about the state of democracy in the United States today? We describe lessons learned from a collaborative course on democratic erosion taught at nearly two dozen universities during the 2017-18 academic year. We use survey data, student-written blog posts, exit questionnaires, and interviews with students who did and did not take the course to explore the effects of studying democratic erosion from a comparative perspective. Do comparisons foster optimism about the relative resilience of American democracy or pessimism about its vulnerability to the same risk factors that have damaged other democracies around the world? Somewhat to our surprise, we find that the course increased optimism about US democracy, instilling greater confidence in the relative strength and longevity of American democratic norms and institutions. We also find, however, that the course did not increase civic engagement and, if anything, appears to have exacerbated skepticism toward activities such as protest. Students who took the course became increasingly sensitive to the possibility that some forms of civic engagement reflect and intensify the same threats to democracy that the course emphasized-especially polarization.

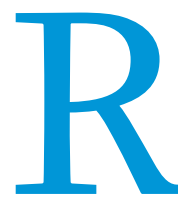

ecent years have witnessed a deluge of commentary warning of imminent threats to democracy in the United States, the West, and the world. To help students and faculty make sense of this unique political moment, we are currently participating in a multi-university collaborative course on democratic erosion. The course encourages students and faculty to evaluate the risks to democracy both here and abroad not through the filter of partisan attachments but rather through the lens of theory, history, and social science. More broadly, the collaboration aims to generate new opportunities for teaching, research, and civic engagement,

Hannah Baron is a PhD candidate in political science at Brown University. She can be reached at hannah_baron@brown.edu.

Robert A. Blair is assistant professor of political science and international and public affairs at Brown University and coordinator of the Democratic Erosion consortium. He can be reached at robert_blair@brown.edu.

Shelby Grossman is assistant professor of political science at the University of Memphis. She can be reached at shelby.grossman@memphis.edu. exploiting economies of scale to pursue avenues of inquiry that might not be accessible through a more conventional class.

Faculty at 19 universities participated in the collaboration during the 2017-18 academic year. Some taught the exact same 13-week course; others incorporated several weeks of material from our shared syllabus into courses on related topics. Students collaborated on a number of assignments, including a crossuniversity blog and a democratic erosion event dataset for USAID. Students also attended a political event of their choosing (e.g., a pro- or anti-Trump rally) and wrote reflections on their experience, which were then shared with all participating universities to allow for comparisons across settings.

This article presents lessons learned from the first year of the collaboration. It has both pedagogical and substantive aims. Pedagogically, we explore the unique challenges and benefits of the collaborative model, which is rare in political science. Substantively, we use a combination of qualitative and quantitative data to assess how studying the dynamics of democratic erosion in other countries shapes opinions about the state of US democracy 
in the Trump era. Does a comparative perspective generate optimism about the relative resilience of democratic norms and institutions in the United States or pessimism about their vulnerability? Does learning about protest and other forms of resistance stimulate commitment to activism or skepticism toward particular modes of civic engagement?

The importance of these questions extends beyond the collaboration. Some scholars have warned of a diminishing commitment to democracy among American (and global) youth, borne out in survey data that tracks perceptions of democracy over time and across generations (although this point is contested) (Foa and Mounk 2016; Voeten 2016). Some argue that waning youth commitment to democratic ideals is a warning sign that democracy itself is at risk (Foa and Mounk 2017). In the past, student mobilization often proved decisive in catalyzing and consolidating democratic reforms; in the future, some are concerned that student apathy will have the opposite effect. The impact of higher education on students' perceptions of US democracy therefore is of urgent practical, pedagogical, and substantive concern.

We found that students were pessimistic about the state of US democracy, regardless of whether they took the course. Somewhat to our surprise, however, students who took the course generally reported becoming more optimistic over time, even as they became more aware of the subtle threats that democracy faces. Students who did not take the course became more pessimistic or did not update their priors one way or the other. Analyzing the United States in comparative perspective seems to have reassured students of the relative strength and longevity of American democracy. This gap between students who did and did not take the course mirrors a similar gap that has emerged in recent surveys (notably Bright Line Watch) that compare experts' perspectives to those of the American public. Finally, we found that students who took the course became more skeptical of the value of certain types of civic engagement (e.g., protest), which many perceived to reflect and exacerbate polarization.
Assignments maximize opportunities for collaboration across universities. In lieu of reading responses, students write posts for our publicly accessible blog (see democratic-erosion.com) using course readings to illuminate recent events in the United States and elsewhere. For one of these posts, students attend a local political event and write a piece reflecting on their experience. They are required to comment on one another's posts as well. The blog allows students to communicate their ideas beyond the classroom and creates continuity across semesters. The best and most topical posts from Fall 2017 were assigned as required readings for Spring 2018; Spring 2018 posts were assigned as required readings for Fall 2018; and so on. The very best posts from 2017-18 also were published as part of the Social Science Research Council's “Democracy Papers” series (see https://items. ssrc.org/category/democracy-papers), alongside essays by Robert Keohane, Ian Shapiro, David Mayhew, and other leading political scientists.

In lieu of final papers, students prepare country case studies that master's students at the Bush School of Government and Public Service at Texas A\&M University then convert into a dataset on the causes, symptoms, and consequences of democratic erosion worldwide. This assignment was developed in collaboration with USAID's Democracy, Human Rights, and Governance section. Texas A\&M students have already published the dataset and presented preliminary results to USAID, the US State Department, and a consortium of NGOs working on democracy promotion. Students at all participating universities were listed as contributors. The dataset, which currently has 823 events from 66 countries (covering 2007-2016), will be expanded during the 2018-19 academic year. To our knowledge, this is the first systematic attempt to record democratic erosion-related events across countries and over time.

The collaboration recently completed its first year. Three universities taught the full 13-week course in Fall 2017-Boston University (BU), Brown University, and the University of

\section{Analyzing the United States in comparative perspective seems to have reassured students of the relative strength and longevity of American democracy.}

\section{UNDERSTANDING THE TRUMP ERA THROUGH A MULTI-UNIVERSITY COLLABORATION}

A group of seven faculty and two research assistants designed the syllabus for the course, which comprises 13 weeks of material divided into six modules. ${ }^{1}$ The first module introduces students to contemporary cases of democratic erosion, focusing on Venezuela, Nicaragua, Poland, and Zambia. The second module canvasses existing definitions and theories of democratic consolidation and erosion. The third module addresses the causes, symptoms, and consequences of democratic erosion-populism and demagoguery; propaganda, disinformation, and the media; polarization; and scapegoating, paranoia, and exclusion. The fourth module explores mechanisms for defending democracy within multiple "sites" of resistance (e.g., the press, the bureaucracy, and civil society). In the fifth module, each instructor devotes three sessions to regional case studies. The sixth module reevaluates US democracy today.
Memphis-and three more integrated elements of our shared syllabus into courses on related topics (Indiana University, Bloomington; Stanford University; and the University of North Carolina, Chapel Hill). Eleven universities taught the full course in Spring 2018, including one in the Philippines. ${ }^{2}$ Five universities incorporated elements of the shared syllabus into related courses. 3 The course was taught in many different formats: lecture and seminar; graduate and undergraduate; entry level and upper level; and quarter length and semester length.

We are unaware of any similar effort to coordinate the design and implementation of a course across so many universities simultaneously. The model has many benefits. Participating faculty share the burden of preparing lectures, discussion questions, and in-class activities, and work collectively to improve lesson plans across semesters. This has proven especially important for those who are not experts on democratic erosion and those who are still early in their teaching careers. Collaborative lesson 
planning eased the uncertainty that each felt venturing into unfamiliar substantive terrain.

Students have benefited from the collaboration as well. Many commented on the appeal of communicating their ideas not only with their professor but also with the public, policy makers, and their peers at other institutions. ${ }^{4}$ Collaboration also created fruitful opportunities for combining teaching with research. With more than 200 students preparing country case studies for the democratic erosion dataset, the collaboration is generating a considerable amount of raw data that we plan to use for research of time trends alone-although our qualitative interviews strongly suggest that the course had an effect.

With these caveats in mind, our survey data indicate that, overall, students who took our course were pessimistic about the state of US democracy and its likely trajectory in the coming year. Across 14 universities, the average student rated the quality of US democracy 6.4 on a scale of 1 to 10 . Of those who took the survey, $49.3 \%$ believed this number would decline during the next year compared to $36.0 \%$ who believed it would stay the same and only $14.7 \%$ who believed it would improve.

\section{Nearly half of the interviewed students who took the course (i.e., six of 14) reported feeling more optimistic about American democracy in February 2018 than they did five months previous.}

purposes-ideally, in collaboration with students. There is surprisingly little cross-national research on the determinants of democratic erosion, and the few existing studies focus on sudden authoritarian reversals (e.g., coups) rather than on the gradual processes of erosion that tend to characterize democracies today (Bermeo 2016; Varol 2015). We hope to help fill this gap.

\section{EXPLAINING STUDENTS' CHANGING PERSPECTIVES ON US DEMOCRACY IN THE TRUMP ERA}

How did studying democratic erosion from a comparative perspective shape students' prognoses for the future of democracy in the United States? We draw on four sources of data to answer this question. First, we administered a "baseline" survey to all enrolled students at the start of the Fall 2017 and Spring 2018 semesters, reaching 298 students across 14 universities. We then reran the survey at the end of the Fall 2017 semester for students at the three universities that taught the full 13-week syllabus (i.e., BU, Brown, and Memphis) and in Spring 2018 at Georgia State University and Ohio State University. Appendix A.3 lists the questions included in these surveys.

Second, we asked students to complete a written "exit questionnaire" at the end of the Fall 2017 semester. 5 We then compiled their responses and searched for recurring themes. Third, we reviewed and coded all of the US-related blog posts that students wrote over the course of the Fall 2017 semester and searched for recurring themes as well. Fourth, in February 2018, we interviewed 26 students at the three universities that taught the full syllabus in 2017. For purposes of comparison, we also interviewed students who did not take the course but who were comparable to those who did. Details about our sampling strategy are in appendix A.2.

Several caveats are warranted. Most important, students self-selected into the course and-although we did our best to interview students who might serve as valid counterfactuals for one another (e.g., comparing Brown students who completed the course to those who attended the first day but did not enroll)these are observational comparisons based on small samples. Small samples are especially problematic for our survey, precluding potentially informative subgroup analyses (e.g., assessing whether students who identify as Republican were more or less likely to change their views over the course of the semester). Finally, we cannot eliminate the possibility that the differences we detected between our "baseline" and "endline" were artifacts
When asked in interviews how their prognoses for American democracy had changed during the Fall 2017 semester, however, we found a marked difference between students who took the course and those who did not. Nearly half of the interviewed students who took the course (i.e., six of 14) reported feeling more optimistic about American democracy in February 2018 than they did five months previous. In contrast, most students who did not take the course either became more pessimistic or-more commonly-did not update their priors. Of the 12 students we interviewed who did not take the course, eight reported that they felt no different about US democracy in February 2018 than they did the previous September. One reported feeling more optimistic and two reported feeling more pessimistic. (One student chose not to respond.)

Suggestive evidence of increased optimism emerged in our comparison of the baseline and endline surveys as well. Figure 1

\section{Figure 1}

Assessment of and Predictions about Quality of Democracy in the United States

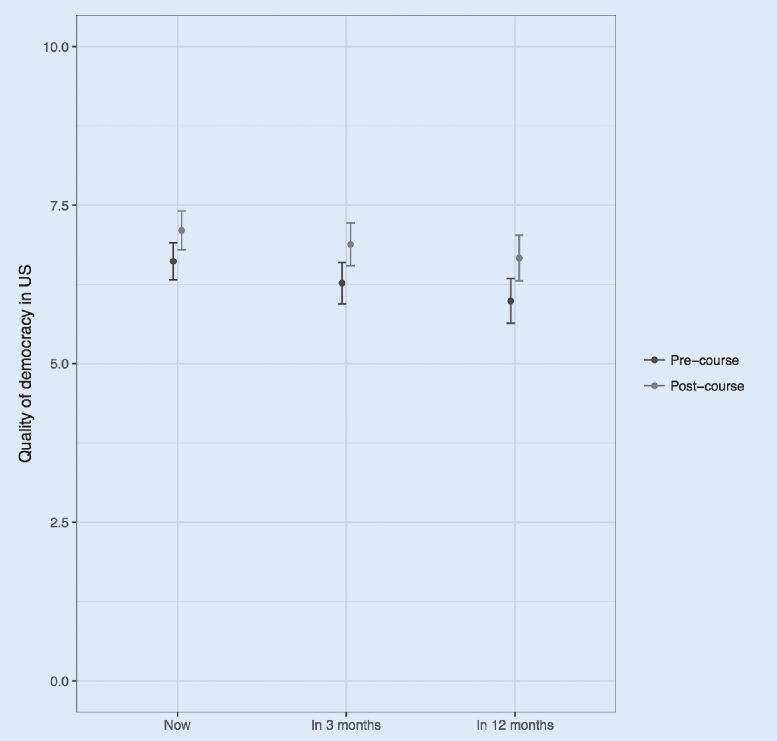

Note: This figure draws on surveys at universities from which we have pre- and post-course data: Boston University (2017), Brown University (2017), Georgia State University (2018), Ohio State University (2018), and University of Memphis (2017). The points are averages and the lines are $95 \%$ confidence intervals. 
shows differences in assessments of the quality of US democracy at the start and at the end of the course, along with differences in predictions for the quality of democracy in three and 12 months. For each estimate, students were about $6 \%$ more optimistic after the course. The differences between the three pre- and postcourse estimates are all statistically significant at the $95 \%$ confidence level.

This increased optimism in some respects is surprising. If anything, we were concerned that the course would exacerbate students' pessimistic priors. Moreover, many students credited the course with increasing their awareness of the subtle threats that democracies face. One student explained that before taking the course, he believed democratic erosion implied a political crisis or power vacuum. "Now I think the process is a lot more nuanced and less visible," he stated. "It's more about gradual change over time."' Similarly, another student noted that whereas democracies can collapse through coups, "erosion more broadly speaking isn't always coups. It's a steady chipping away."

Students who did not take the course, in contrast, tended to characterize democratic erosion in terms of "rapid and radical change" (Bermeo 2016, 6). In general, this perspective was conducive to optimism. One student who did not take the course felt sanguine about the state of democracy in America because "Trump and the administration haven't done anything to explicitly $[\ldots]$ indicate that we won't have another election." ${ }^{\text {A Another }}$ felt reassured by the checks and balances in the American political system and would be concerned only if "someone literally wanted to rip out pages of the constitution."9

Intuitively, we would have expected greater awareness of the subtleties of democratic erosion to provoke greater concern for the resilience of our own democratic institutions. After all, the risk of a coup in the United States is almost certainly very low, whereas the risk of executive overreach and other more insidious forms of erosion is arguably much higher. However, among our students at least, awareness of these threats seems to have had the opposite effect. What explains this apparent paradox?

We believe that the most likely explanation lies in the course's comparative focus. In the interviews, when asked to compare the United States to other countries, most students (69\%) found cause for optimism in the comparisons they drew, regardless of whether they took the course. Students who took the course, however, were much more likely to draw these comparisons in the first place and to believe that comparisons are informative. Indeed, one third of the students who did not take the course explicitly stated that the experiences of other countries are not relevant for understanding democratic erosion in the United
American exceptionalism and about the impossibility of gleaning lessons from comparative cases.

Not a single student who took the course expressed this view. To the contrary, as one of our students succinctly stated, "[h] aving studied backsliding in other countries, the US could be so much worse." ${ }^{11}$ Another explained that "[b]efore the course, I didn't give those [institutional and societal] bulwarks against democratic erosion enough credit. But after learning of the lack thereof in countries around the world, I have renewed confidence in our own." ${ }^{12}$ Comparing the United States to democracies in the developing world, another student noted that "[t]he strength of preexisting political institutions makes the election of Trump far less worrisome [...]. Take Trump and put him in a democracy like Liberia's, his presidency would be far more consequential." ${ }_{13}$ In other words, assessing the United States in comparative perspective elicited optimism among students, regardless of whether they took the course. However, students who took the course were more likely to engage in this type of comparative exercise and to believe it is worthwhile.

Our finding that the course increased students' optimism also resonates with results from the Bright Line Watch (BLW) surveys, which consistently show that experts tend to rate the performance of US democracy much less negatively than the public. ${ }^{14}$ The same factors that explain the discrepancy between experts and the public in BLW also may explain the gap between students who did and did not take our course. Experts are more likely to evaluate American democracy from a comparative perspectiveprecisely the perspective that we encouraged our students to adopt. Although students who took our course are not "experts," they are better informed than those who did not. Parallels with BLW suggest that our findings may not be specific to these particular students and instead may be indicative of a more general relationship between optimism and expertise.

\section{UNDERSTANDING STUDENTS' ATTITUDES TOWARD PROTEST AND CIVIC ENGAGEMENT}

What do students' changing perspectives on American democracy imply for their willingness to participate in civic action against democratic erosion in the future? Our interviews suggest that students' increasing optimism about US democracy was matched by increasing skepticism about the value of protest and other forms of activism, especially when compared to students who did not take the course. Two thirds of students who did not take the course expressed strongly positive views about the role protest plays in safeguarding democracy, compared to one half of students who took the course. As one student who took the course

\section{Our interviews suggest that students' increasing optimism about US democracy was matched by increasing skepticism about the value of protest and other forms of activism, especially when compared to students who did not take the course.}

States. For example, when asked if he felt more or less optimistic about American democracy when thinking about other countries, one student who did not take the course stated, "I wouldn't say it makes me feel any way in either direction. I think that's because I feel like America is a superpower in its own way." ${ }^{10}$ Other students who did not take the course expressed similar sentiments about explained, he "settled on [protests and marches] not doing much policy wise." ${ }^{15}$

Other students expressed similar reservations, often informed by their experiences of civic engagement during the course. Students became more sensitive to the possibility that some forms of civic engagement reflect and exacerbate the same subtle, 
long-term threats to democracy that the course emphasizedespecially polarization. Reflecting on the March for Racial Justice in Providence, Rhode Island, for example, a Brown student noted that to even hear about the event, one would have to occupy left-leaning circles. The march may have mobilized like-minded individuals, but it did little to convince skeptics-or even engage them in dialogue (Duane-McGlashan 2017).

When asked how they planned to participate in politics in the future, students' responses were lukewarm. Most said they planned to vote, attend lectures on political topics, and engage others in political conversations. In general, however, they expressed surprisingly little enthusiasm for the forms of civic engagement that are most accessible to students: protesting, attending town hall meetings, and calling elected representatives, for example.

Instead, students who took the course tended to express hope in "bureaucratic resistance"-that is, defiance against potentially antidemocratic policies by civil servants operating from within the government, often at the local level. Students wrote blog posts praising recent examples of bureaucratic resistance in New York (Jarrell 2017b), California (Hilliard 2017), and Maine (Jarrell 2017a). As one student explained, " $[\mathrm{t}]$ he bureaucracy currently serves an important role in preserving democratic standards when threatened by executive policy" (Karibjanian 2017). Other students expressed similar views.

This increased skepticism toward civic engagement and increased faith in bureaucratic resistance in some respects is unsurprising, given our previous findings. As students who took the course became more optimistic about American democracy, they may have become less convinced of the need for protest. Similarly, as they became more attuned to subtle threats to democratic institutions, they may have concluded that those threats must be neutralized in equally subtle ways, from within the institutions. Whatever the explanation, and however preliminary our findings, they do point to a potentially unintended consequence of the course. By requiring that students attend political events, we hoped to instill greater interest in civic engagement. If anything, however, the course seems to have accomplished the opposite.

A large literature examines the sources of political protest ${ }^{16}$ and the conditions that drive protest success. ${ }^{17}$ Most analysts regard protest as normatively positive: a tool for individuals to assert rights to freedom of speech and assembly; a way for the government to hear minority opinions; and a channel to constrain and even topple unrepresentative regimes. However, in times of growing polarization, protest also may undermine cross-partisan social ties and cooperation, which could further deepen polarization. The students' reactions to protest in a moment of high polarization suggest a potentially fruitful avenue for research on the conditions under which particular types of civic engagement have these inadvertent consequences.

\section{CONCLUSION}

The collaboration is continuing in the 2018-19 academic year and beyond. We and the other participating faculty are pursuing several opportunities to expand the project and to develop new venues for collaboration, including a student conference on democratic erosion held in August 2018 and a partnership with BLW that encourages students to use survey data as raw material for their own writing and analysis. We are also increasing the number and diversity of participating universities in the United States and elsewhere.

This article demonstrates that considering politics in other countries can shape students' appraisals of their own political environment and, more specifically, that viewing the United States in comparative perspective can make students more confident in American political norms and institutions. We also show, however, that participating in protest in moments of high polarization can cause students to become disillusioned about the utility of this form of civic engagement as a mechanism for political change-a topic that we believe merits further study.

\section{SUPPLEMENTARY MATERIAL}

To view supplementary material for this article, please visit https://doi.org/10.1017/S1049096518002123

\section{ACKNOWLEDGMENTS}

This research received IRB approval from the University of Memphis IRB\# PRO-FY2018-396. We thank the faculty who taught this course in 2017 and 2018, in particular Steven Rosenzweig, who connected us with many of his students for this article. We also thank the students who took the course, especially those who agreed to be interviewed for this article. To learn more about the democratic erosion collaboration, see democratic-erosion.com or contact Robert Blair at robert_blair@brown.edu. .

\section{NOTES}

1. Reading lists posted by academics in the wake of Trump's election informed the syllabus. See appendix A.1 for examples.

2. American University (School of International Service); Columbia University; Georgia State University; Ohio State University; Skidmore College; Texas A\&M University (Bush School of Government and Public Service); University of Denver; University of Memphis; University of Pennsylvania; University of the Philippines, Diliman; and Yale University. One version of the course was taught for master's-level students at Memphis in the Fall and another was taught for undergraduates in the Spring.

3. Indiana University, Bloomington; Texas A\&M University; University of California, Davis; University of California, Los Angeles; and University of Virginia.

4. Interview by email with faculty member A on March 4, 2018.

5. See appendix A.4 for the full exit-questionnaire prompt.

6. Interview with student E on February 7, 2018.

7. Interview with student $Q$ on February 12, 2018.

8. Interview with student $\mathrm{G}$ on February 7, 2018.

9. Interview with student $\mathrm{N}$ on February 9, 2018.

10. Interview with student $\mathrm{G}$ on February $7,2018$.

11. University of Memphis exit questionnaire on December 4, 2017.

12. Student II exit questionnaire on December 7, 2017.

13. Student EE exit questionnaire on December 7, 2017.

14. See http://brightlinewatch.org/wave7/.

15. Interview with student $C$ on February 6, 2018.

16. See, for example, Baldez (2002) and Tarrow (1989).

17. See, for example, Chenoweth and Stephan (2012) and Kitschelt (1986).

\section{REFERENCES}

Baldez, Lisa. 2002. Why Women Protest: Women's Movements in Chile. Cambridge, UK: Cambridge University Press.

Bermeo, Nancy. 2016. “On Democratic Backsliding." Journal of Democracy 27 (1): 5-19.

Chenoweth, Erica, and Maria J. Stephan. 2012. Why Civil Resistance Works: The Strategic Logic of Nonviolent Conflict. Reprint. New York: Columbia University Press.

Duane-McGlashan, Cody. 2017. "March for Racial Justice, Rhode Island: Solidarity, Not Resistance." Democratic Erosion. Available at http://democratic-erosion. com/2017/11/17/march-for-racial-justice-rhode-island-solidarity-not-resistance (accessed March 6, 2018) 
Foa, Roberto Stefan, and Yascha Mounk. 2016. "The Democratic Disconnect.” Journal of Democracy 27 (3): 5-17.

Foa, Roberto Stefan, and Yascha Mounk. 2017. "The Signs of Deconsolidation." Journal of Democracy 28 (1): 5-15.

Hilliard, Lauren. 2017. “Jerry Brown...Trump's Biggest Opponent.” Democratic Erosion. Available at http://democratic-erosion.com/2017/11/15/jerry-brown-trumps-biggest-opponent-by-lauren-hilliard-boston-university (accessed March 6, 2018).

Jarrell, Matthew. 2017a. "A State of Chaos: Maine Fights for Democracy." Democratic Erosion. Available at http://democratic-erosion.com/2017/11/o8/a-stateof-chaos-maine-fights-for-democracy-by-matthew-jarrell-brown-university (accessed March 6, 2018).

Jarrell, Matthew. 2017b. "Reflections on Public Service and Democracy with Preet Bharara." Democratic Erosion. Available at http://democratic-erosion. com/2017/11/14/reflections-on-public-service-and-democracy-withpreet-bharara-by-matthew-jarrell-brown-university (accessed March 6, 2018).
Karibjanian, Isabela. 2017. "Why Bureaucratic Resistance Is Not a Fundamenta Threat to Democracy." Democratic Erosion. Available at http://democratic-erosion. com/2017/12/12/why-bureaucratic-resistance-is-not-a-fundamental-threat-todemocracy-by-isabela-karibjanian-brown-university (accessed March 6 , 2018).

Kitschelt, Herbert P. 1986. "Political Opportunity Structures and Political Protest Anti-Nuclear Movements in Four Democracies." British Journal of Political Science 16 (1): 57-85.

Tarrow, Sidney. 1989. Democracy and Disorder: Protest and Politics in Italy 1965-1975. New York: Oxford University Press.

Varol, Ozan. 2015. “Stealth Authoritarianism.” Iowa Law Review 100 (4): 1673-1742.

Voeten, Erik. 2016. “Are People Really Turning Away from Democracy?” Rochester, NY: Social Science Research Network Scholarly Paper 2882878. Available at https://papers.ssrn.com/abstract=2882878 (accessed March 3, 2018) 